\title{
VARIATION OF CAR CABIN TEMPERATURE INFLUENCED BY VENTILATION UNDER DIRECT SUN EXPOSURE
}

\author{
M.S.F. Mansor ${ }^{1}$, U.Z. Abd Rahman ${ }^{1, *}$, M.S. Zainal Abidin ${ }^{1}$, M.Z. Md Zain ${ }^{2}$ \\ and M.R. Md Yusof ${ }^{1}$ \\ ${ }^{1}$ Research Department, Engineering Division, \\ Perusahaan Otomobil Nasional (PROTON) Sdn. Bhd. \\ HICOM Industrial Estate, Batu 3, P.O. Box 7100, \\ 40918, Selangor Darul Ehsan, Malaysia. \\ *Email: zulaikar@proton.com \\ ${ }^{2}$ Department of Applied Mechanics and Design, \\ Faculty of Mechanical Engineering \\ Universiti Teknologi Malaysia, \\ 81310 UTM Skudai, Johor, Malaysia.
}

\begin{abstract}
In the past few years many fatalities have been reported as the result of internal car heat. Problems arise when the temperature in a car cabin is too hot when parked under direct sunlight. The trapped and accumulated heat causes the temperature inside a car to reach up to $36^{\circ} \mathrm{C}$ and even up to $50^{\circ} \mathrm{C}$. The objectives of this paper are to study and analyze the behavior of car cabin temperature influenced by ventilation under direct sun exposure. The performance of the proposed mathematical modelling was compared to data collected in real time from the car cabin. The simulation model was used to study the behavior of cabin temperature by investigating the ventilation mass flow rate as its parameter. An experimental result was obtained from measurements on a salon car parked in the direct sun. It is hoped that this study will be able to provide beneficial information for car interior design and material selection in order to improve comfort levels in cars.
\end{abstract}

Keywords: Car cabin temperature; ventilation mass flow rate; sun exposure; car comfort.

\section{INTRODUCTION}

Many researchers agree that the heat generated in a vehicle cabin can be increased to $80^{\circ} \mathrm{C}$ in the interior when it is parked indirect sunlight (Al-Kayiem, Sidik, \& Munusammy, 2010). This experience causes an uncomfortable sensation in the driver in the first ten minutes after entering a vehicle that has been in the sun for a prolonged period of time (Grundstein, Dowd, \& Meentemeyer, 2010). Drivers then need to run an air conditioner at high speed in order to reduce the high temperature and maintain comfort in the vehicle cabin (Grundstein, Meentemeyer, \& Dowd, 2009). This scenario will increase the thermal load of the air conditioning system and subsequently increase fuel consumption of the vehicle, as well as increasing carbon dioxide, $\mathrm{CO}_{2}$, emissions (Saidur, Sattar, \& Masjuki, 2008). Global environmental policies prioritize the reduction of $\mathrm{CO}_{2}$ emissions from light-duty vehicles. As a result, new $\mathrm{CO}_{2}$ legislation is enforced across Europe in order to support these policies and thus lead a campaign against global warming to save the environment (Son \& Park, 2010). Recently, the Europe Union has 
agreed to limit $\mathrm{CO}_{2}$ emissions to $130 \mathrm{~g} / \mathrm{km}$ from light-duty vehicles, with progressive implementation from 2012 to 2015 (European Parliament, 2009). Vehicle manufacturers worldwide have therefore incorporated technological improvements in order to fulfil this requirement, such as engine size reduction, low-rolling-resistance tires, weight lightening, improved aerodynamics, and hybridization and electrification of vehicles (Fonseca, Casanova, \& Valdés, 2011).COC technology has thus been introduced to support this requirement, where this technology facilitates the driver to minimize the operating of fans when entering the vehicle, and thus decreasing the thermal load of air conditioning. According to the Kyoto protocol to the United Nations Framework Convention on Climate Change, the environmental regulations in vehicles have been strengthened in order to prevent global warming. Lately, the need for energy reduction technology has appeared before the development of an alternative energy technology due to renewable energy in the occupied part of the total energy in 2020 is predicted to be approximately $1 \%$ (Son \& Park, 2010). The COC technology is believed to be one part of energy reduction technology in vehicles where the compressor is operated at minimum performance when the fun blower is slow. This will lead to decreasing the fuel consumption of the vehicle.

There are many methods that can be used to decrease cabin temperature, including installing solar-powered air ventilators, the use of sunshades when it is sunny, and installing the solar reflective films or window tints. Theoretically, solar-powered air ventilators help to decrease cabin temperature by removing hot air from the cabin and replacing it with cooler fresh air. This method is capable of reducing the ambient cabin air temperature at the windshield and the dashboard by up to $8.3^{\circ} \mathrm{C}$ on average (Bishop et al., 2007; Henein, Taraza, Chalhoub, Lai, \& Bryzik, 2000). Research into the use of sunshades during sunshine has been conducted by Manning \& Ewing (2009) and AlKayiem et al. (2010), and the effect of sunshades has proved to be significant. In order to reduce the amount of infrared visible light, and ultraviolet (UV) radiation entering the vehicle windows, solar reflective films are applied to the interior of flat glass windows. (Rugh, Farrington, \& Boettcher, 2001; Rugh, Hendricks, \& Koram, 2001) report that the ambient temperature can be reduced in the range of $1.8^{\circ} \mathrm{C}$ to $4.6^{\circ} \mathrm{C}$ using solar reflective films. The objective of this research was to study and analyze the behavior of car cabin temperature as influenced by ventilation under direct sun exposure. New methods and products to solve overheating in vehicle cabins could be designed as a result of this research.

\section{EXPERIMENTAL PROCEDURES}

Experimentation was carried out between $4^{\text {th }}$ December 2012 and $3^{\text {rd }}$ March 2013 in the open parking area of the main plant of a national car manufacturer. The objectives of the experiment were to obtain temperature data and analyze the behavior inside idling vehicles when the windows are closed and when they are opened slightly when exposed to direct sunlight. Two cars of the same model, features and color from a national car manufacture (Car A as the benchmark and Car B as the test car) were used in the experiment. Three temperature sensors were placed in each car as shown in Figure 1. The first sensor was placed near the roof interior area, the second sensor was placed near the air-breath area and the third sensor was located on the vehicle floor. Another sensor was located outside the vehicles to take ambient temperature readings. 


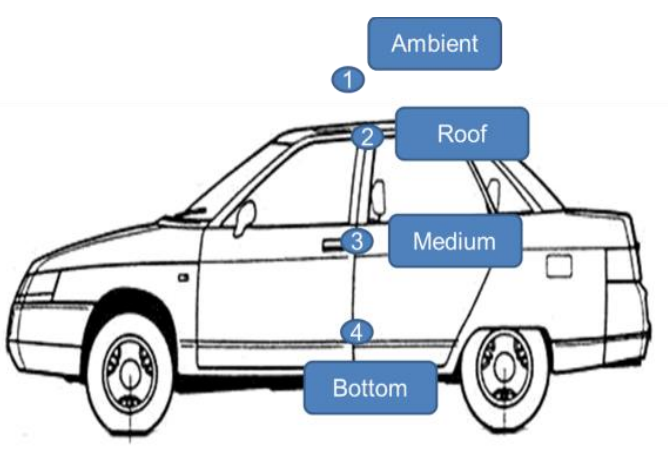

(a)

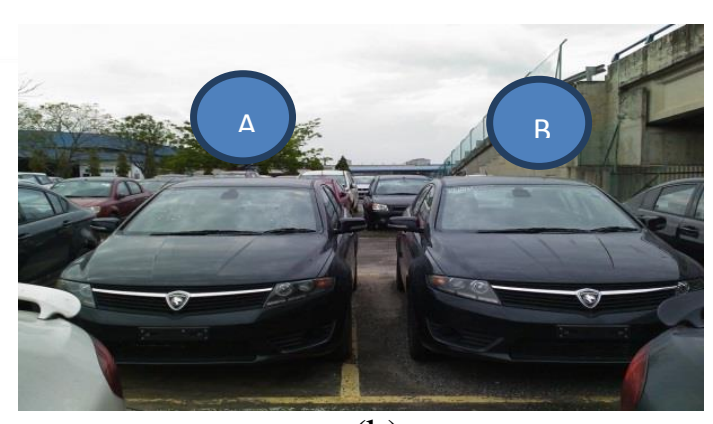

(b)

Figure 1.Location of the sensors (a), in Car A and Car B (b).

The equipment used in the experiment were sensors (TM 35) and data acquisition (Texas Instruments). The data obtained were then analyzed. The ambient wind flow rate was first recorded using a Pro's KitMT-4015 flow rate meter. Theoretical results have shown that when the mass flow rate is increased, the cabin temperature is decreased and vice versa (Figure 2).

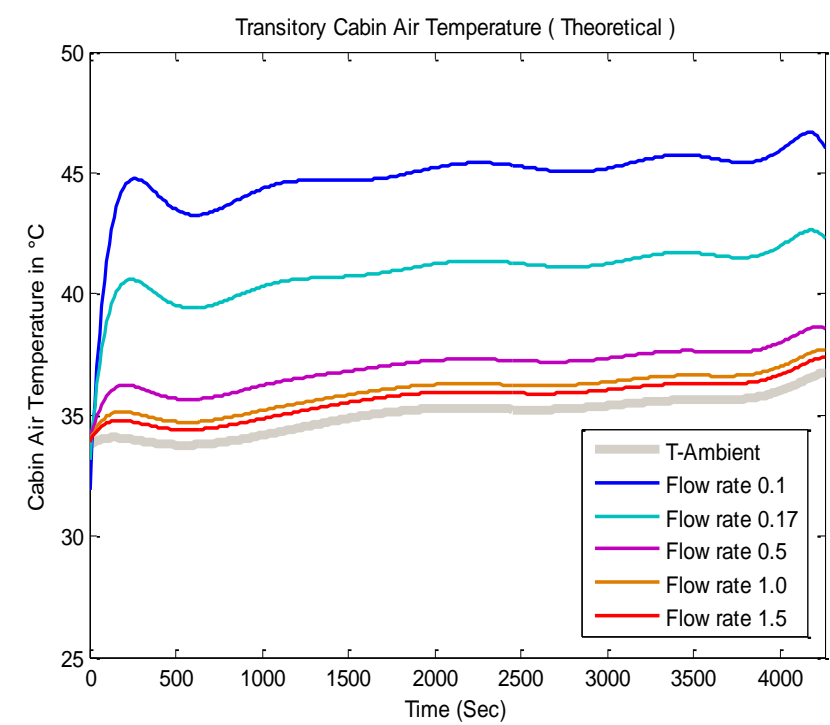

Figure 2.Theoretical performance of adjustment on mass flow rate.

The test was carried out under three conditions.

Condition 1: Only one front right window open by $15 \mathrm{~mm}$

Condition 2: Only one rear right window open by $15 \mathrm{~mm}$

Condition 3: One front right window and one rear right window open simultaneously by $15 \mathrm{~mm}$.

\section{MATHEMATICAL MODELING}

Before the experiment was conducted, the mathematical modeling was created. This mathematical modeling is very important in order to compare the theoretical values with the data collected from real time in the car cabin. Based on the mathematical modeling, the simulation model was developed in order to study the behavior of cabin temperature 
by investigating the ventilation mass flow rate as its parameter. The model of thermal dynamics for a small cabin was then developed from the energy analysis thermal equation as (Konz, 2007):

$$
m c_{p} \frac{d T}{d t}=\dot{m} c_{p} T_{i n}-\dot{m} c_{p} T+\dot{Q}
$$

Where $m$ represents the cabin air mass $(\mathrm{kg}) ; \dot{m}$ represents mass flow rate $(\mathrm{kg} / \mathrm{s}) ; c_{p}$ represents specification capacity coefficient $(\mathrm{KJ} / \mathrm{kg} . \mathrm{K}) ; T_{\text {in }}$ represents temperature of the air entering (K); $T$ represents temperature in the cabin $(\mathrm{K})$, transforming the equation to

$$
\frac{d T}{d t}=\frac{\dot{m} c_{p}}{m c_{p}} T_{i n}-\frac{\dot{m} c_{p}}{m c_{p}} T+\frac{\dot{Q}}{m c_{p}}
$$

Resulting in a standard differential equation of the type

$$
\dot{T}=x T(x)+y u(t)
$$

With the coefficients $x=-\frac{\dot{m} c_{p}}{m c_{p}}$ and $y=\frac{\dot{m} c_{p}}{m c_{p}} T_{i n}+\frac{\dot{Q}}{m c_{p}}$

$$
T(t)=T_{0} e^{x t}+\frac{y}{x\left(e^{x t}-1\right)}
$$

The total heat flow rate is defined as $\dot{Q}_{\text {Total }}=\dot{Q}_{\text {Winds }}$

$$
\dot{Q}=\dot{Q}_{\text {Convection }}+\dot{Q}_{\text {Radiation }}
$$

Where $\begin{aligned} & \dot{Q}_{\text {Convection }}=h A\left(T_{s}-T_{\infty}\right) ; \dot{Q}_{\text {Radiation }}=\varepsilon A \sigma\left(T_{s}^{4}-T_{\text {surr }}^{4}\right) \\ & \dot{Q}_{\text {Radiation }}=\dot{Q}_{\operatorname{Re} \text { flection }}+\dot{Q}_{\text {Absorption }}+\dot{Q}_{\text {Transmisson }} ; \dot{Q}_{\text {Transmissin }}=\tau \dot{Q}_{\text {Radiation }}=\tau \varepsilon \sigma A T^{4}\end{aligned} ;$

From Eq. (6) the basic concept of radiation can be divided into three phenomena (Figure 3). This research focusses on only the heat flow rate for transmission the heat effect is bigger than the other heat. From this mathematical derivation, the simulation model was developed to study the effects of vehicle interior temperature in the cabin. Two parameters were investigated, ventilation mass flow rate and heat flow rate.

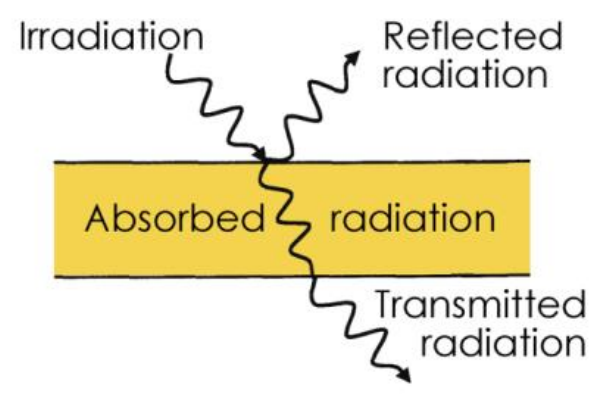

Figure 3. Absorption, reflection, and transmission by real surface (Theodore, Adrienne, Frank, \& David, 2011) 
Table 1. Parameters used in simulation.

\begin{tabular}{lc}
\hline \multicolumn{1}{c}{ Parameter } & Value \\
\hline$T_{\text {cabin }}$ & $25^{\circ} \mathrm{C}$ \\
$T_{\text {ambient }}$ & $34^{\circ} \mathrm{C}$ \\
Volume & $2.96 \mathrm{~m}^{\mathbf{3}}$ \\
Density of air & $1.17 \frac{\mathrm{kg}}{\mathrm{m}^{3}}$ \\
Heat flow by convection and radiation & $\dot{Q}_{\text {Total }} \approx 1000 \mathrm{Watt}$ \\
\end{tabular}

\section{RESULTS AND DISCUSSION}

\section{First Condition}

The experiment was carried out from 10:30am until 11:40am. The intensity of sunlight at this hour is considered to be medium, and the highest ambient temperature recorded was $35^{\circ} \mathrm{C}$. In Figure 4, the temperature is shown as increased in all sensor locations. The highest cabin temperature in Car $\mathrm{A}$ is $50^{\circ} \mathrm{C}$, obtained from the sensor placed near the roof area. As seen in Figure 5, the same phenomena was observed in Car B, and the highest temperature recorded was $45^{\circ} \mathrm{C}$, obtained near the air breath area. The graph shows that the temperature recorded from the three sensors was similar because the air from outside flows inside the car cabin. Thus, the hot temperature can be reduced since the air will circulate from outside to inside simultaneously.

When one front window is opened by $15 \mathrm{~mm}$, the temperature inside Car B was $3^{\circ} \mathrm{C}$ to $5^{\circ} \mathrm{C}$ lower than that in $\mathrm{A}$, as seen in Figure 6. The graph also shows that the cabin temperature is higher that the ambient temperature due to the heat absorption by car components such as the dashboard and car cushion.

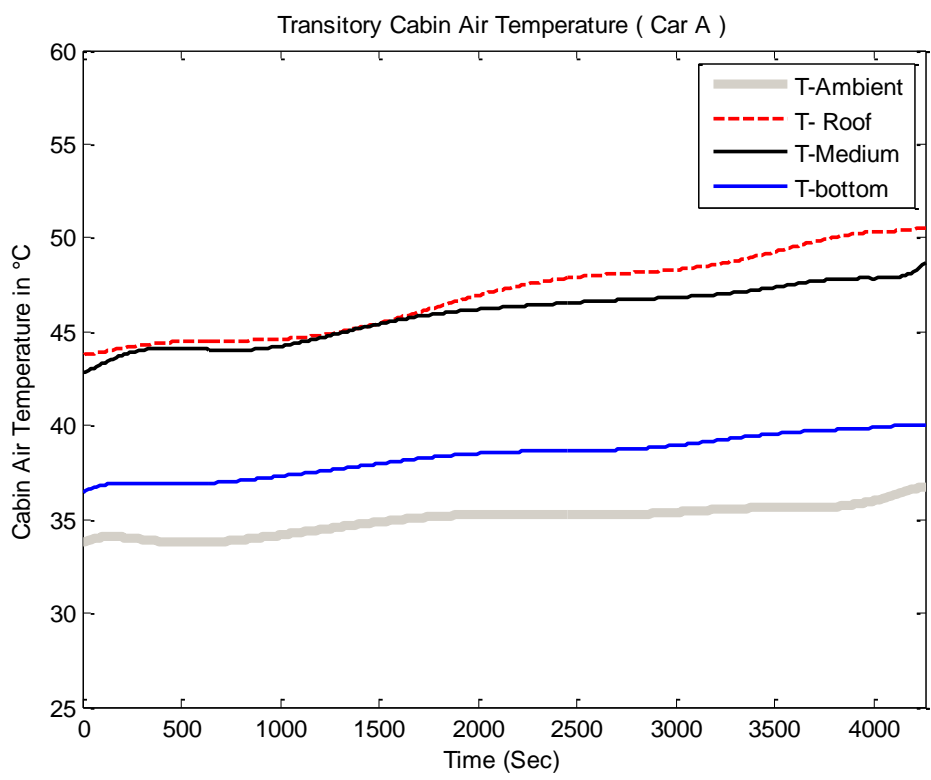

Figure 4. Cabin temperature of Car A. 


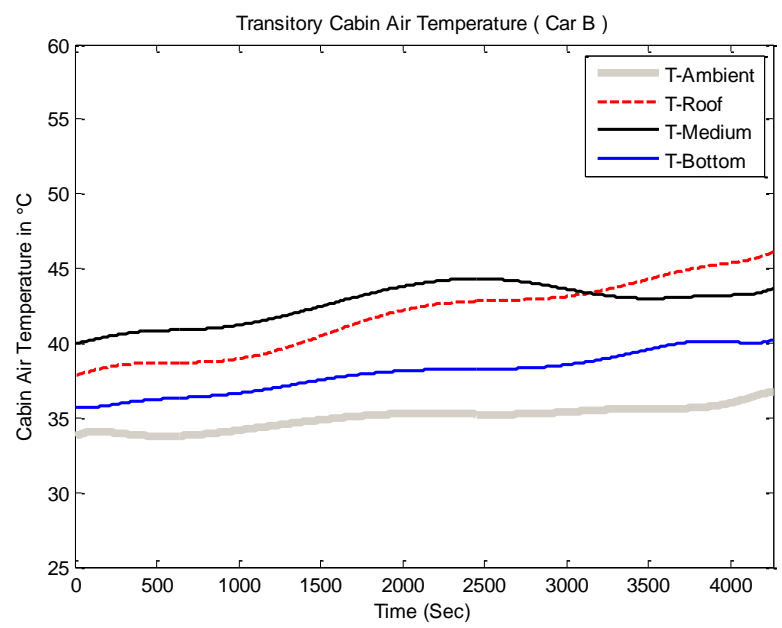

Figure 5.Cabin temperature of Car B (with only one front window opened by $15 \mathrm{~mm}$ ).

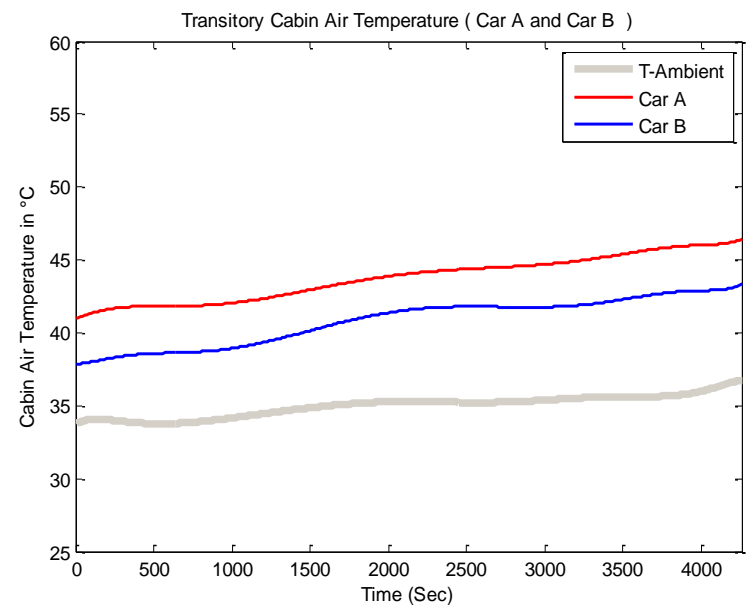

Figure 6. Average cabin temperature of Car A and Car B.

\section{Second Condition}

The test under the second condition was performed from 12:00 noon until12:30pm. At this hour, the intensity of the sunlight can be considered high, and the ambient temperature recorded was $40^{\circ} \mathrm{C}$. As seen in Figure 7, the temperature in Car A was recorded as increased in all three sensor locations and decreased after 1400 seconds. The highest temperature was $60^{\circ} \mathrm{C}$, near the roof area. The temperature was higher at the roof compared to other locations because this location is directly exposed to the sun.

With one rear window open by $15 \mathrm{~mm}$, the highest temperature in Car B, as seen in Figure 8, was also found to be $60^{\circ} \mathrm{C}$, near the roof area. The temperature reading in the floor area of Car B gave almost the same result as in Car A. However, the temperature near the air breath area in Car B showed a decrease of $2^{\circ} \mathrm{C}$ to $5^{\circ} \mathrm{C}$, compared to Car A. The average temperature difference between both cars is quite small, between $0^{\circ} \mathrm{C}$ to $3^{\circ} \mathrm{C}$, as seen in Figure 9. The temperature difference is small because the area of the window is small compared to the front window. Thus, the air circulation is less and will affect the temperature inside the car cabin. 


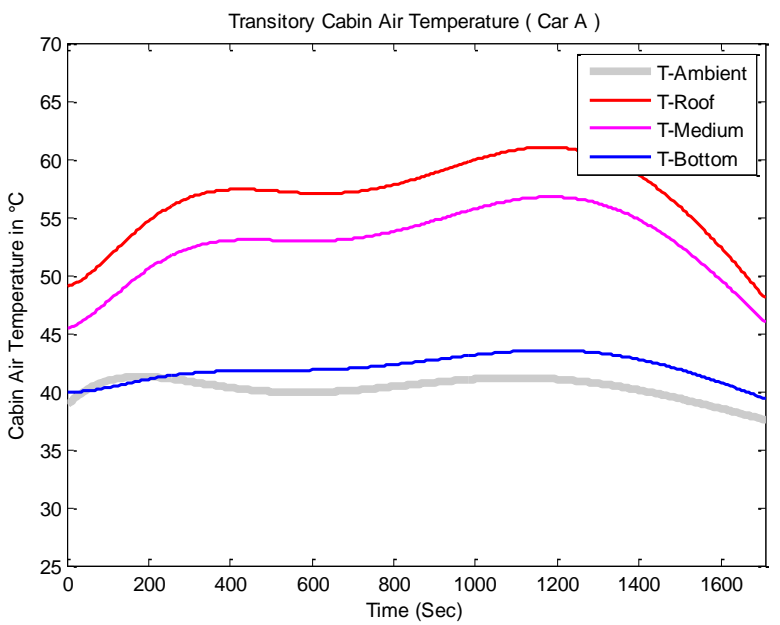

Figure 7.Cabin temperature of Car A.

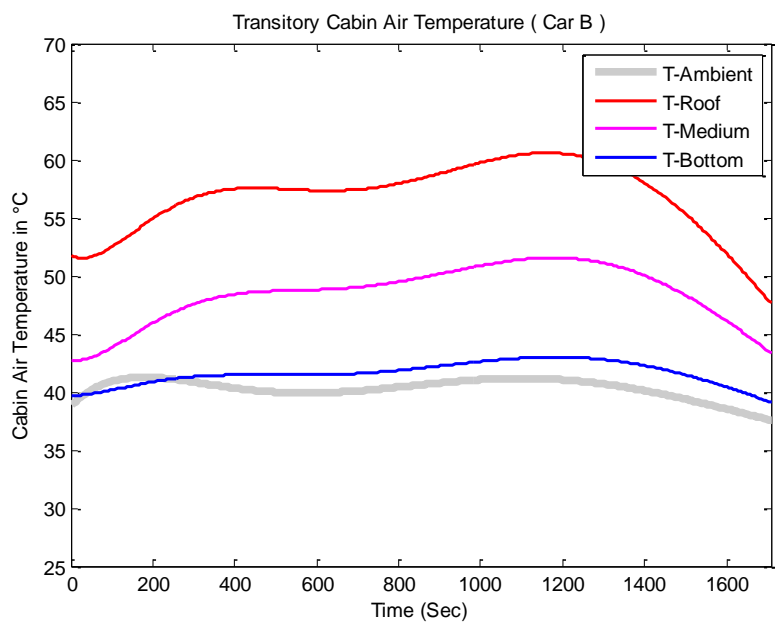

Figure 8.Cabin temperature of Car B (with only one rear window open by $15 \mathrm{~mm}$ ).

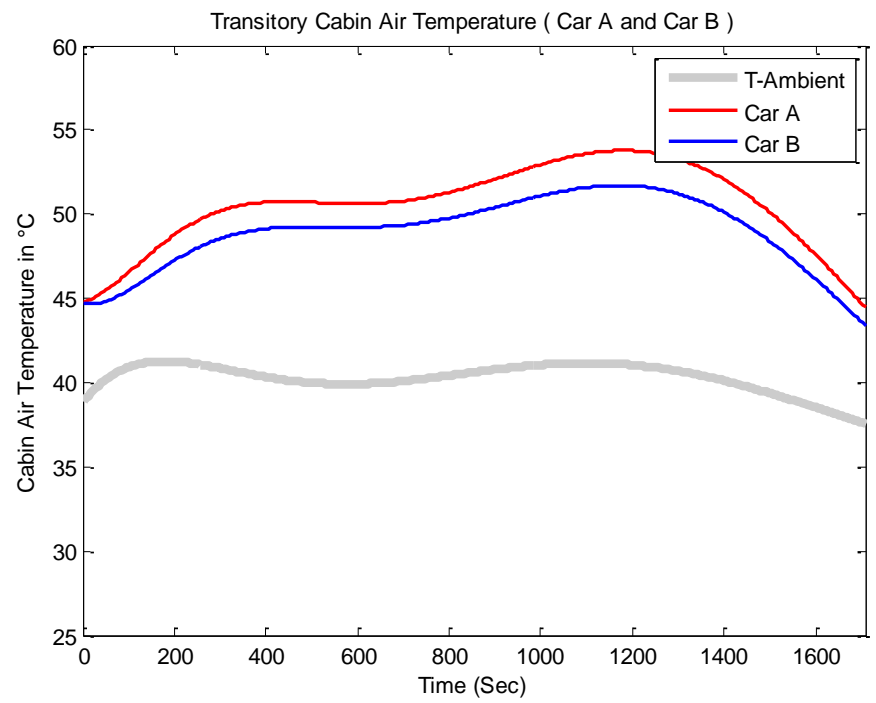

Figure 9. Average cabin temperature of Car A and Car B. 


\section{Third Condition}

Under this condition, the test was executed from $2.00 \mathrm{pm}$ until $3.00 \mathrm{pm}$, when the intensity of the sunlight is assumed to be at its maximum level. The ambient temperature recorded was between $35^{\circ} \mathrm{C}$ to $40^{\circ} \mathrm{C}$. As seen in Figure 10, in Car A, the temperature from all three sensors was recorded as increased and stable from 1800 seconds until the end of the experiment. The temperature near the roof and air breath areas increased rapidly up to $60^{\circ} \mathrm{C}$ at 500 to 1000 seconds. Meanwhile, as seen in Figure 11, the maximum temperature near the roof area was recorded at $63^{\circ} \mathrm{C}$, which gives a higher value than that of Car A. The temperature near air breath area decreased by $5^{\circ} \mathrm{C}$ to $7^{\circ} \mathrm{C}$, however, compared to the same area in Car A. As seen in Figure 12, the average temperature difference between Cars $\mathrm{A}$ and $\mathrm{B}$, when one front and one rear window is opened simultaneously by $15 \mathrm{~mm}$, is between $0^{\circ} \mathrm{C}$ to $4^{\circ} \mathrm{C}$. The reading showed that, even though the front and rear windows were opened simultaneously by $15 \mathrm{~mm}$, the temperature reading on average did not show a significant difference as it did in the first condition.

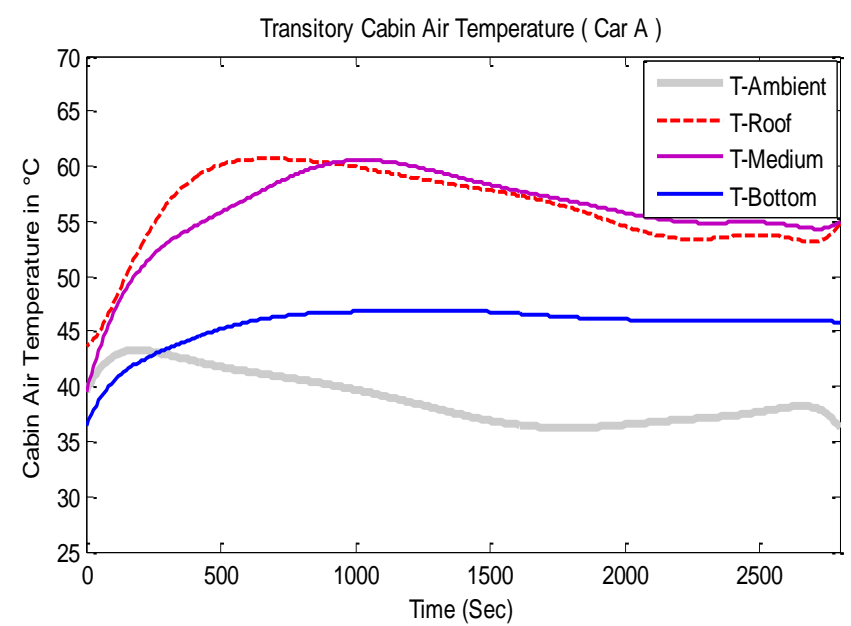

Figure 10.Cabin temperature of car A.

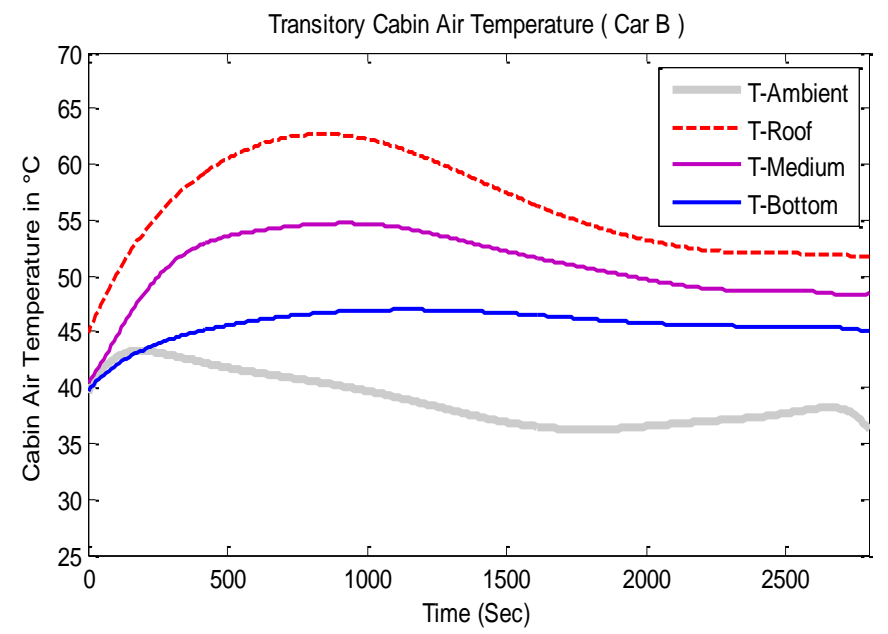

Figure 11.Cabin temperature of Car B (with one front window and one rear window open simultaneously by $15 \mathrm{~mm}$ ). 
It can be seen from the results obtained for all three conditions, that the temperature inside the vehicle is reduced when the window is opened. The greatest temperature difference, of from $3^{\circ} \mathrm{C}$ to $5^{\circ} \mathrm{C}$ was obtained when only one front window was opened. This is because the front window opening area is larger than the rear window. Opening the front window will allow a higher flow rate of air to circulate inside the car cabin. The second highest range of temperature difference was recorded when one front and one rear window was opened simultaneously, with values of $0^{\circ} \mathrm{C}$ to $4^{\circ} \mathrm{C}$. This value was expected to be quite high because two windows are open. However, it is assumed that the hot air that flows from the front window to the ambient air outside was punched back in through the rear window by moving air in the surroundings. The temperature difference was therefore average. Finally when one rear window was opened, the temperature difference was $0^{\circ} \mathrm{C}$ to $3^{\circ} \mathrm{C}$, which is the lowest value. This is due to the smallest opening area being at the rear window, compared to Conditions 1 and 3. Readings may be changed if there are other factors that can improve the ventilation and movement of hot air inside the car, for example by using a ventilation fan in the car.

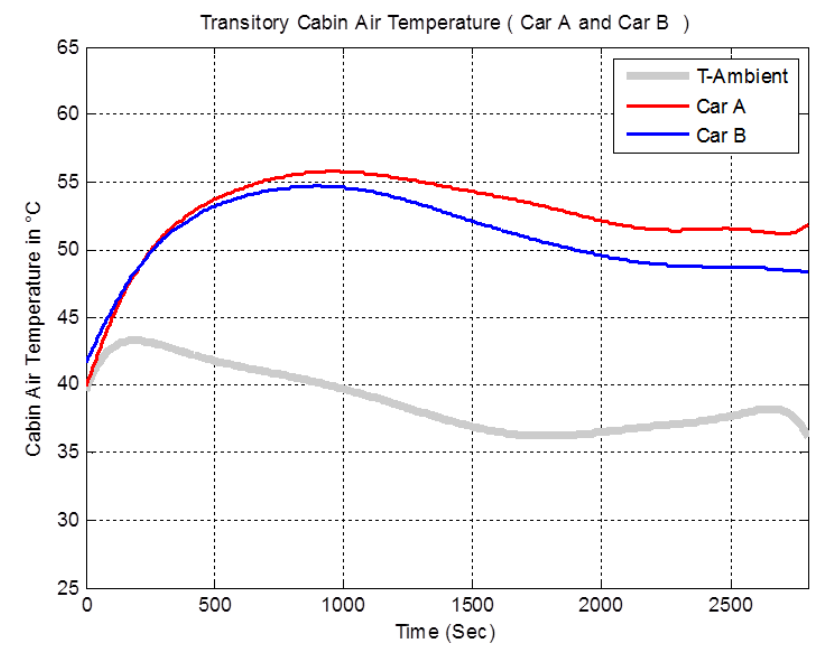

Figure 12.Average cabin temperature of Car A and Car B

\section{CONCLUSIONS}

The behavior of the natural hot air ventilation in car cabin, when the idle car is exposed to direct sunlight have been studied. It was found that the cabin temperature can reach up to $60^{\circ} \mathrm{C}$ after less than half an hour's exposure to direct sunlight at various sunlight intensity. Other factors such as ambient wind velocity, natural conduction, natural convection and radiation also influenced the behavior of the temperature. When one front window was opened, the highest temperature difference was obtained. This was followed by the values obtained when one front and one rear window were opened simultaneously, and when one rear window was opened. It is suggested that the reduction of the cabin temperature will be accelerated if there is a ventilation fan to vent the hot air out oft he vehicle. Further study can be conducted in order to overcome the overheating problem, such as a study of the design of fans, proper planning of the battery or energy management and the evaluation of a control strategy. 


\section{ACKNOWLEDGEMENTS}

The authors would like to thank the Research Department, Engineering Division, PROTON and UTM for the financial support for this project and permission to publish the work.

\section{REFERENCES}

Al-Kayiem, H. H., Sidik, M. F., \& Munusammy, Y. R. (2010). Study on the thermal accumulation and distribution inside a parked car cabin. American Journal of Applied Sciences, 7(6), 784-789.

Bishop, J., Nedungadi, A., Ostrowski, G., Surampudi, B., Armiroli, P., \& Taspinar, E. (2007). An engine start/stop system for improved fuel economy: SAE Technical Paper.

European Parliament. (2009). Setting emission performance standards for new passenger cars as part of the community's integrated approach to reduce CO2emissions from light-duty vehicles. (Regulation (EC) No. 443/2009 of the European Parliament and of the Council). Official Journal of the European Union.

Fonseca, N., Casanova, J., \& Valdés, M. (2011). Influence of the stop/start system on $\mathrm{CO} 2$ emissions of a diesel vehicle in urban traffic. Transportation Research Part D: Transport and Environment, 16(2), 194-200.

Grundstein, A., Dowd, J., \& Meentemeyer, V. (2010). Quantifying the Heat-Related Hazard for Children in Motor Vehicles. Bulletin of the American Meteorological Society, 91(9), 1186-1191.

Grundstein, A., Meentemeyer, V., \& Dowd, J. (2009). Maximum vehicle cabin temperatures under different meteorological conditions. International journal of biometeorology, 53(3), 255-261.

Henein, N. A., Taraza, D., Chalhoub, N., Lai, M.-C., \& Bryzik, W. (2000). Exploration of the contribution of the start/stop transients in HEV operation and emissions: SAE Technical Paper.

Konz, M. (2007). Generic simulation of energy consumption of automobile air conditioning systems. Retrieved from http://hdl.handle.net/10948/129

Manning, R., Ewing, J. (2009). .RACQ Vehicles Technologies. (2009). Temperatures in cars survey. RACQ Vehicles Technologies, 1-21.

Rugh, J. P., Farrington, R. B., \& Boettcher, J. A. (2001). The impact of metal-free solar reflective film on vehicle climate control. Paper presented at the SAE Conference Proceedings P.

Rugh, J. P., Hendricks, T. J., \& Koram, K. (2001). Effect of solar reflective glazing on Ford Explorer climate control, fuel economy, and emissions. Paper presented at the Proceedings of the International Body Engineering Conference.

Saidur, R., Sattar, M. A., \& Masjuki, H. H. (2008). Performance of an improved solar car ventilator. Paper presented at the GMSARN International Conference on Sustainable Development: Issues and Prospects for the GMS.

Son, M., \& Park, B.-J. (2010). Proactive stop and start technology for high gas mileage of the used car. Paper presented at the Vehicular Technology Conference Fall (VTC 2010-Fall), 2010 IEEE 72nd.

Theodore, L. B., Adrienne, S. L., Frank, P. I., \& David, P. D. (2011). Fundamentals of heat and mass transfer (Vol. 7th ed.). New Jersey: John Wiley \& Sons. 